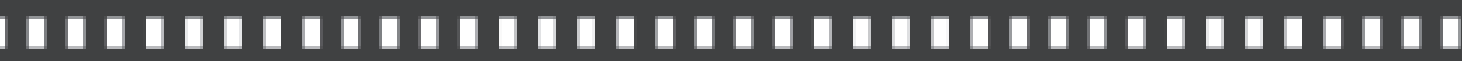 0 realismo entre as tecnologias da imagem e os regimes de visualidade: fotografia, cinema e a "virada imagética" do Século XIX

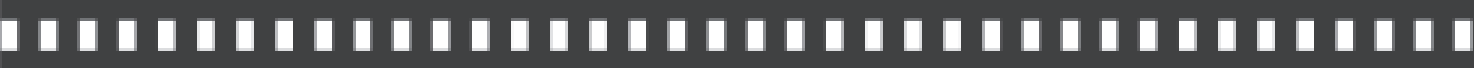

Daniel B. Portugal 


\title{
0 realismo entre as tecnologias da imagem e os regimes de visualidade: fotografia, cinema e a "virada imagética" do Século XIX
}

The realism between the image technologies and the scopic regimes: photography, cinema and the "imagery turnaround" of the $19^{\text {th }}$ century

\author{
Daniel B. Portugal *
}

Resumo: $O$ artigo começa com uma discussão de cunho teóricometodológico acerca da relação entre regimes de visualidade e tecnologias da imagem. Em seguida, questiona a objetividade da noção de "realismo" e, rechaçando o determinismo tecnológico, procura analisar algumas transformações históricas que afetaram profundamente os regimes de visualidade do século XIX e que podem ajudar a explicar porque, neste momento, tornou-se viável, pensável e desejável o desenvolvimento da fotografia e, posteriormente, do cinema.

Palavras-chave: Regimes de visualidade. Tecnologias da imagem. Fotografia. Cinema.

\begin{abstract}
The article begins with a discussion of theoretical and methodological concerning about the relation between scopic regimes and image technologies. Then, it questions the objectivity of the notion of realism and, avoiding technological deterministic approaches, seeks to analyze some historical transformations that deeply affect the scopic regimes in the $19^{\text {th }}$ century and that may help to explain why, in this specific moment, the development of the photography and afterwards, of the cinema became viable, thinkable and desirable.
\end{abstract}

Keywords: Scopic regimes. Image technology. Photography. Cinema.

* Doutorando em Comunicação e Cultura pela Universidade Federal do Rio de Janeiro (UFRJ). Mestre em Comunicação e Práticas de Consumo pela Escola Superior de Propaganda e Marketing (ESPM) de São Paulo. 
Figura 1 - Aula de modelo vivo egípcia

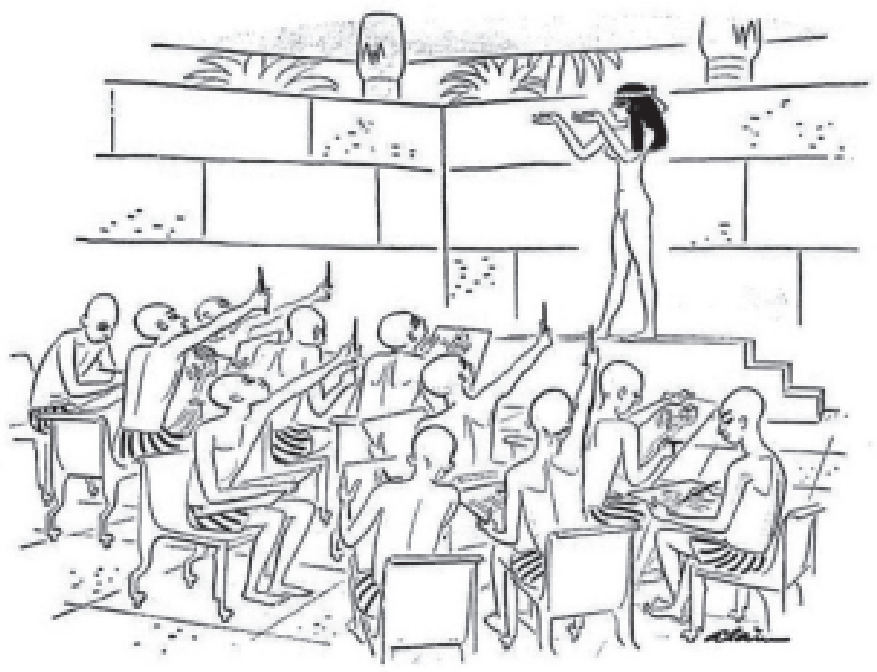

Desenho: ALAIN, 1955

Fonte: The New Yorker Magazine Inc.

A imagem reproduzida na figura 1 parece-nos um excelente ponto de partida para as reflexões que queremos desenvolver neste artigo, relacionadas aos modos de ver e de representar visualmente o mundo, bem como às formas de "decodificar" e "entender" representações visuais. Gombrich (2007) utiliza tal imagem na introdução de seu livro Arte e ilusão para formular algumas das perguntas que guiarão esta sua obra e que também servirão como um eixo para nosso estudo. São elas:

Por que diferentes idades e diferentes países representaram o mundo visível de maneira tão distinta? As pinturas [e fotografias] que hoje consideramos fiéis à realidade parecerão tão pouco convincentes para futuras gerações como a pintura egípcia para nós? Será inteiramente subjetivo tudo que diz respeito à arte ou haverá padrões objetivos na matéria? E se houver, se os métodos ensinados hoje nas classes de modelo vivo resultam em imitações mais fiéis da natureza que as convenções adotadas pelos egípcios, por que os egípcios não as adotaram? Será possível, como sugere nosso cartunista, que eles percebessem a natureza de modo 
diverso? E essa variabilidade da visão artística não nos ajudaria a explicar também as desnorteadoras imagens criadas pelos artistas contemporâneos? (GOMBRICH, 2007, p.3).

Já tangenciamos algumas destas questões em outros textos, nos quais observarmos o caráter criativo das imagens visuais, sejam mentais, sejam gráficas. Argumentamos que, para que transponhamos estímulos em imagens coerentes, com forma, cores etc., necessitamos de um aprendizado sensorial baseado na experiência empírica e em certas "regras" socioculturais que estruturem tais experiências ${ }^{1}$. Chamamos os conjuntos dessas "regras" de regimes de visualidade. Importante notar que tais "regras", de caráter mais propriamente estético, se imbricarão ainda com as circulações de significados, orientadas por outra enorme gama de padrões socioculturais.

Os regimes de visualidade estão ligados, assim, à relação que os grupos nos quais um observador se insere estabelecem com as imagens, ou seja, ao papel que as imagens desempenham na "realidade" social daquele que olha: com o que está relacionado o ato de olhar? Por que se olha? O que se espera ver, ou ainda, o que "existe" nesta "realidade" para se ver? Como se deve agir frente ao que se vê? Como construir as semelhanças ou agrupar visualmente as coisas? Quando se produz uma imagem gráfica, o que se deve representar e como se deve representar?

Seguindo esse raciocínio, podemos dizer que o uso da expressão "regime de visualidade" pressupõe uma abordagem socioconstrucionista,

\footnotetext{
${ }^{1}$ Um excelente exemplo para explicitar esta perspectiva encontra-se no relato de Oliver Sacks (1995) sobre o caso de Virgil. Virtualmente cego desde a infância - a densa catarata só lhe permitia uma vaga percepção da luminosidade ambiente -, ele foi operado e recuperou a visão. "Mas quando Virgil abriu os olhos, depois de ter sido cego por 45 anos - tendo um pouco mais que a experiência visual de uma criança de colo, há muito esquecida -, não havia memórias visuais em que apoiar a percepção; não havia mundo algum de experiência e sentido esperando-o. Ele viu, mas o que viu não tinha qualquer coerência." (SACKS, 1995, p.129). A primeira visão de Virgil após a operação deve ter sido semelhante àquela do hipotético observador que Schopenhauer (2003) imagina "momentaneamente privado de todo intelecto". Sem "intelecto", ou seja, sem o entendimento, tal observador não pode mais ver a bela paisagem que admirava: nada lhe restou "a não ser a sensação de um estímulo muito variado de sua retina, semelhante a diversas manchas cromáticas numa paleta de pintor, o que seria, por assim dizer, a matéria bruta da qual seu intelecto criou há pouco tal visão". (SCHOPENHAUER, 2003, p.32).
} 
entendendo tal classificação da maneira mais genérica possível, e evitando cair em radicalismos. Não é uma abordagem inteiramente distinta da adotada por Gombrich na obra mencionada, ainda que haja algumas diferenças - Gombrich (2007) dá a entender, por exemplo, que os egípcios não produziam representações "realistas" porque não dispunham de um acervo de técnicas/esquemas que permitissem a produção de tais representações, de modo que o que é "fácil para nós" não seria "fácil para eles", isto é, para "eles" que eram "primitivos". Como argumentaremos em seguida, entretanto, mais do que a facilidade ou dificuldade (de todo modo relativas) de produzir tais representações "realistas", cabe perguntar onde e quando elas são desejáveis, efetivamente produzidas e, acima de tudo, vistas como imagens realistas.

Interessa-nos fugir da ótica evolucionista implícita na obra de Gombrich e propor uma perspectiva mais explicitamente preocupada com as dinâmicas do consumo de imagens - e, assim, com o observador/ espectador como sujeito inserido numa realidade social específica - e com os processos comunicacionais.

Voltando às perguntas feitas por Gombrich (2007), e procurando respondê-las, talvez fique mais fácil expor os pressupostos da análise que aqui realizaremos aqui. Sobre a primeira pergunta ${ }^{2}$, diríamos que as formas de representar o mundo visível mudam de acordo com os regimes de visualidade de cada época e de cada lugar. Obviamente, tal resposta não explica muita coisa, seu principal mérito é o de indicar que, para estudar tais mudanças, não se deve procurar uma fórmula geral, e sim particularidades sócio-históricas - tecnológicas e epistemológicas - que possam esclarecer algumas mudanças específicas nestes regimes. Esse é, grosso modo, o método utilizado por Jonathan Crary (1992) em seu estudo sobre as "técnicas do observador" no século XIX, obra que será uma das principais referências em nossas reflexões deste artigo.

\footnotetext{
2 "Por que diferentes idades e diferentes países representaram o mundo visível de maneira tão distinta?"
} 
Sobre a segunda pergunta ${ }^{3}$, mais do que respondê-la, seria interessante notar que, como o próprio Gombrich dá a entender depois, há outra mais importante: as gerações futuras se relacionarão com as imagens com base na noção de fidelidade à realidade? Para que digamos que uma imagem é mais ou menos realista, é necessário encará-la como uma "janela para o mundo", e este, obviamente, não é o único modo de olhar uma imagem, como se pode depreender de relações às vezes estabelecidas com imagens tão diversas quanto os desenhos egípcios, os semáforos de pedestre nas avenidas, o bezerro de ouro dos hebreus, os quadros abstratos, os gráficos e diagramas utilizados em artigos científicos etc.

A terceira ${ }^{4}$ é, na verdade, uma pergunta filosófica, e tudo o que poderíamos dizer em relação a ela é que, ao estudar as imagens, devemos nos ater ao mundo fenomênico e que não nos aventuraremos a tratar de uma suposta coisa em si que pudesse ser vista de um ponto de vista totalizante e inteiramente objetivo. Adotamos, nesse sentido, uma perspectiva kantiana. E, em tal perspectiva, a pergunta posta já não faz muito sentido, assim como a subsequente ${ }^{5}$. Caberia perguntar: o que significa dizer que algo é "mais fiel" à realidade? Mais fiel em que sentido? Uma casca de árvore não poderia ser considerada, em certo aspecto, uma representação "mais fiel" da árvore do que uma fotografia da mesma? Em resumo: uma coisa só é mais ou menos fiel a outra coisa com base em um critério de fidelidade (não necessariamente um critério racional/ conceitual, mas um critério sensível), e é exatamente tal critério que, segundo nossa argumentação, varia de uma época e cultura para outra. Ou seja, o realismo, como o entendemos hoje, não é algo dado objetivamente por sua semelhança ou "fidelidade" a uma realidade dada, ele só emerge no seio de um regime de visualidade específico.

\footnotetext{
3 “As pinturas [e fotografias] que hoje consideramos fiéis à realidade parecerão tão pouco convincentes para futuras gerações como a pintura egípcia para nós?"

4 "Será inteiramente subjetivo tudo que diz respeito à arte ou haverá padrões objetivos na matéria?"

5 "E se houver, se os métodos ensinados hoje nas classes de modelo vivo resultam em imitações mais fiéis da natureza que as convenções adotadas pelos egípcios, por que os egípcios não as adotaram?"
} 
Quanto à quinta pergunta ${ }^{6}$, já a respondemos afirmativamente. Vale ressaltar, entretanto, que dizer que os egípcios percebiam a natureza de modo diverso não é o mesmo que dizer que eles desenhavam aquilo que percebiam da mesma forma que nós desenharíamos se percebêssemos o mesmo que eles; e muito menos, como na figura 1, que eles desenhavam o que percebiam com as mesmas técnicas que utilizamos nas aulas de modelo vivo. De fato, como nota Mitchell (1994, p.44), ao comentar esse cartum da "aula de modelo vivo egípcia":

[...] o ponto principal do cartum é que os estudantes de arte egípcios não são mostrados como diferentes, mas se comportam exatamente como estudantes de arte ocidentais e modernos o fazem na tradicional aula de modelo vivo. [...]. Eles aparecem desenhando exatamente o que vêem, não algum estereótipo ou esquema conceitual. O que é engraçado no cartum, parece-me, não é que egípcios antigos apareçam (como poderíamos esperar) como seres exóticos, estranhos, diferentes de nós, mas que apareçam (contrariamente às expectativas) sendo exatamente como nós. ${ }^{7}$

Assim, não devemos encarar este "ver o mundo de forma diferente" como uma solução para o problema do realismo na representação visual, pois não há nenhum motivo para que, considerada esta diferente forma de ver, postulemos que as outras dimensões da relação que os egípcios estabeleciam com as imagens identifiquem-se com as nossas - que postulemos, por exemplo, que eles representavam exatamente "o que viam".

Por fim, no que se refere à última pergunta ${ }^{8}$, acreditamos que a resposta é afirmativa, que um estudo sobre os regimes de visualidade pode jogar luz não apenas sobre as imagens da arte contemporânea, mas também sobre outras imagens que não costumam ser caracterizadas como

\footnotetext{
6 "Será possível, como sugere nosso cartunista, que eles percebessem a natureza de modo diverso?" ${ }^{7}$ Tradução livre do original: [...] the whole point of the cartoon is that the Egyptian art students are not shown as different at all, but behave just as modern, western art students do in a traditional life-class. [...]. They are shown drawing exactly what they see, not some "stereotype" or conceptual schema. What is funny about the cartoon, I take it, is not that ancient Egyptians are shown (as we might expect) to be exotic, alien, and different from us, but that they are shown (against all expectation) to be just like us.

8 "Essa variabilidade da visão artística não nos ajudaria a explicar também as desnorteadoras imagens criadas pelos artistas contemporâneos?"
} 
artísticas, mas com as quais interagimos cotidianamente-quais sejam, as imagens midiáticas. É com base nessa convicção que, aqui, propomo-nos a realizar um estudo desta natureza. Ao fazê-lo, não teremos, evidentemente, a pretensão de reconstruir toda uma história dos regimes de visualidade. Concentraremo-nos em certas mudanças que teriam ocorrido nos regimes de visualidade no século XIX (no ocidente, e especialmente na Europa ocidental) e que teriam sido cruciais na estruturação dos regimes de visualidade ocidentais contemporâneos. Poderíamos dizer, para usar uma expressão de Mitchell, que ocorre aí uma "virada imagética". 9

Para desenvolver este estudo, tomaremos como guias principais dois autores: Crary e Aumont. O primeiro, ao estudar a mencionada "virada", anuncia que escreveu sua reflexão no meio de outra "virada imagética" ainda maior:

Esse é um livro sobre visão e sua construção histórica. Apesar de abordar principalmente eventos e ocorrências de antes de 1850, ele foi escrito no meio de uma transformação na natureza da visualidade provavelmente mais profunda do que a que separa a iconografia medieval da perspectiva da renascença. $\mathrm{O}$ rápido desenvolvimento em pouco mais de uma década de uma gama de técnicas de computação gráfica é parte de uma radical reconfiguração das relações entre um sujeito observador e modos de representação que efetivamente anula a maioria dos significados culturalmente estabelecidos dos termos observador e representação ${ }^{10}$. (CRARY, 1992, p.1).

\footnotetext{
${ }^{9}$ Inicialmente usando a expressão para se referir a uma "virada" essencialmente contemporânea, que seguiria a "virada lingüística" proposta por Richard Rorty, Mitchell (1994, p.13, tradução livre do original) diz que o que justifica a noção de uma "virada imagética" (pictorial turn) é que a imagem torna-se "[...] um ponto de peculiar friç̧ão e desconforto junto a uma larga faixa de questionamentos intelectuais". Posteriormente, entretanto, o autor torna a noção mais abrangente, de modo a englobar os diversos momentos da história em que a imagem assumiu papel central canalizando tensões sociais - em bizâncio, nos séculos VII e VIII, por exemplo, na famosa "querela das imagens", e, como argumentamos aqui, também no século XIX. Esta seria a versão recorrente da "virada imagética". (MITCHELL, 2009).

${ }_{10}$ Tradução livre do original: This is a book about vision and its historical construction. Although it primarily addresses events and developments before 1850 , it was written in the midst of a transformation in the nature of visuality probably more profound than the break that separates medieval imagery from renaissance perspective. The rapid development in little more than a decade of a vast array of computer graphics techniques is part of a sweeping reconfiguration of relations between an observing subject and modes of representation that effectively nullifies most of the culturally established meanings of the terms observer and representation.
} 
Neste artigo, seguiremos o autor em sua decisão de apenas mencionar esta rápida transformação contemporânea. Acreditamos que tal menção pode ser útil como uma base de comparação que talvez colabore para esclarecer a natureza das mudanças que se operaram no século XIX. Se, no trecho citado acima, Crary (1992) enfatiza o advento da imagem digital (um novo tipo de imagem técnica), no século XIX, é a própria imagem técnica que surge.

Muito já se escreveu sobre os desdobramentos do advento da imagem técnica, o estudo mais conhecido sendo, provavelmente, o de Walter Benjamin (2000), A obra de arte na era de sua reprodutibilidade técnica, no qual o pensador aponta um "enfraquecimento da aura" que seguiria a reprodução exacerbada das obras de arte. Os diversos estudos com enfoque semelhante ao de Benjamin, entretanto, não costumam analisar as transformações nos regimes de visualidade que teriam permitido o advento da imagem técnica. Talvez por isso, para alguns, tal imagem tenda a adquirir o status de uma creatio ex nihilo e seus desdobramentos acabem sendo vistos sob a ótica de um determinismo técnico. Narrativas paradigmáticas desse olhar são os mitos de assombro com a "nova imagem", que aparece como algo inteiramente diferente de qualquer coisa que já se tivesse visto. No caso do cinema, o mais famoso desses mitos conta o pavor e a fuga desvairada dos primeiros espectadores de $A$ chegada de um trem à estação, filme de Lumière. Mesmo se considerássemos que há base para a história, entretanto, não caberia considerá-la um indicador do caráter totalmente extraordinário da imagem. Não que ela não impressione e não possa engendrar esses "efeitos de realidade" de que fala Aumont (2004, p.31):

[...] um [dos espectadores das primeiras projeções de Lumière] vê, por exemplo, as barras de ferro 'incandescerem' (em Ferradores), outro vê as cenas reproduzidas 'com as cores da vida'; de todos os relatos [sobre essas projeções] que li, não há um sequer que lamente $[\ldots]$ só ter visto uma imagem cinza. 


\section{Queremos apontar apenas que esses "efeitos de realidade"} dependem tanto da materialidade da imagem e das características estruturais do aparelho biológico da espécie humana quanto dos regimes de visualidade que permitem que o espectador veja tal materialidade como imagem $\mathrm{e}$, acima de tudo, como imagem realista.

Voltando à questão da "novidade" da imagem cinematográfica, veremos que o observador do fim do século XIX já estava mais do que acostumado a interagir com uma gigantesca gama de "dispositivos ópticos" como o thaumatrópio, o estereoscópio, o estroboscópio, o zootrópio etc. - falaremos deles adiante -, e ainda com dispositivos como o diorama ${ }^{11} \mathrm{e}$ o panorama ${ }^{12}$ e com os "shows de fantasmagoria"13. Arlindo Machado (1997, p.23) mostra a estreita vinculação do cinema com alguns desses dispositivos:

Se encararmos o cinema como um sistema particular de recursos expressivos em que se tem, de um lado, a sintetização do movimento e da duração pela rápida exibição de imagens fixas separadas e, de outro, a projeção dessas imagens numa tela branca instalada dentro de uma sala escura, com o respectivo acompanhamento sonoro, para uma grande audiência, naturalmente devemos incluir em tal categoria não apenas os

${ }^{11}$ Diorama é um nome que se aplica a diversos dispositivos que visavam uma apresentação extremamente "realista" de imagens, normalmente grandes pinturas, utilizando, para tanto (além, obviamente, das técnicas pictóricas), jogo de luzes, adaptação do espaço de exposição (com telas curvas, por exemplo), materiais específicos como telas translúcidas, vidros etc. O primeiro dispositivo a receber o nome "Diorama", de acordo com R. Derek Wood (1993), foi inaugurado por Daguerre e seu parceiro Charles Bouton, em Paris, em 1822. Na obra citada, o autor descreve cuidadosamente tal dispositivo.

${ }^{12} \mathrm{O}$ panorama foi, segundo Aumont (2004), um dos espetáculos mais apreciados no século XIX. Consistia em pinturas megalomaniacamente gigantescas expostas normalmente em locações especialmente construídas a custos elevados. "Poder-se-ia, simplificando, falar de um panorama à européia, que consiste em uma imagem circular contemplada de uma pequena plataforma central, e de um panorama à americana, constituído por uma imagem plana que se desenrola diante do espectador." (AUMONT, 2004, p.55-56, grifos do autor).

${ }^{13} \mathrm{O}$ "show de fantasmagoria" foi retratado de modo interessante no filme $O$ ilusionista (E.U.A./ República Tcheca, 2006, direção de Neil Burger). Para uma descrição textual, citemos Sarmiento (2002): "um espetáculo de Fantasmagorias utilizava-se de vários fantascópios [projetores rudimentáres, derivados das lanternas mágicas], cujas projeções, ora atrás de telas, ora na superfície vaporosa de gazes comburentes, cresciam e diminuíam conforme a proximidade do projetor, recheado de fantasmas e criaturas malignas. Tudo movimentava-se, avolumando-se, sumindo-se no ambiente sombrio da sala". 
arrepiantes espetáculos de fantasmagoria do belga ÉtienneGaspard Robert (apelidado Robertson; final do século XVIII), não apenas os extraordinários desenhos animados de longa-metragem do teatro óptico do francês Émile Reynaud (meados do século XIX), mas também a tradição inteira da lanterna mágica (desde o século XVII).

Assim, não devemos cometer o erro de tratar o cinema ou a fotografia - ou, de resto, qualquer nova mídia - como uma invenção sem precedentes que, aparecendo como que por geração espontânea, vem determinar (numa visão determinista) novos regimes sensoriais e simbólicos. Como coloca Mitchell (2005, p.215, tradução livre do original), em certo aspecto, “as novas mídias não remapeiam nossos sentidos tanto quanto analisam a operação dos sentidos já construídos pela natureza pelo hábito e pelas mídias anteriores e tentam assemelharse a elas".

Por outro lado, não convém cometer o erro oposto e não considerar novidade alguma. As novas mídias não apenas possuem suas especificidades técnicas como também ganharão um status específico na prática e no imaginário social. Ao refletir sobre as primeiras projeções de Lumière, Aumont (2004, p.34) comenta:

[...] por esse transbordamento de realidade [relacionada à proliferação quase infinita dos detalhes], a vista Lumière escapa, de saída, de uma parte de sua herança - o brinquedo, o zootrópio, o fantascópio, o divertimento baudelairiano -, e passa, de saída para o lado da arte, mesmo que ainda uma arte menor.

Algo semelhante ocorre com a fotografia. Sabe-se que a camera obscura há muito era utilizada pelos pintores como instrumento de trabalho (HOCKNEY, 2002) e que estes muitas vezes tentaram reproduzir a imagem projetada. Ainda assim, é inegável que a possibilidade de fixação automática da projeção luminosa muda muita coisa, a começar pela substituição das manchas de tinta pelas manchas químicas. Cabe, portanto, perguntar o que mudou com o advento da fotografia, mas cabe também - 
e, para nosso estudo, esta é, das duas, a questão principal - perguntar sob que circunstâncias históricas tornou-se viável, pensável e desejável a invenção da fotografia - uma vez mais, não se deve partir do princípio que "sempre" se buscou inventar a fotografia, a suposta "imagem realista por excelência", e, portanto, que seu advento dependeria apenas de "progressos técnicos".

É preciso [...] colocar de saída que a condição de possibilidade (não digo, portanto, é claro, a causa) da invenção da fotografia é, a princípio, que outros tipos de imagens - diferentes daquelas saturadas de sentido e de escritura, do Egito - fosse desejável em uma sociedade, e, mais precisamente, lá onde se produzem as imagens, ou seja: no início do século XIX, na pintura. Assim, a determinação mais direta da invenção da fotografia deve ser lida em certas mudanças ideológicas maiores que afetaram a pintura em torno de 1800. (AUMONT, 2004, p.48).

Essas mudanças "ideológicas” remetem ao que Aumont chama de "mobilização do olhar" e que Crary (1992) denomina "desenraizamento" da visão - a raiz da qual se liberta sendo, aqui, o modelo inflexível e supostamente objetivo da camera obscura.

Se a camera obscura, como um conceito, subsistiu como um terreno objetivo da verdade visual, uma variedade de discursos e práticas - na filosofia, ciência, e nos procedimentos de normatização social - tendem a abolir as fundações desse terreno no início do século XIX. Em certo sentido, o que ocorre é uma nova valoração da experiência visual: ela ganha uma mobilidade e uma maleabilidade sem precedentes, abstraídas de qualquer raiz ou referente. ${ }^{14}$ (CRARY, 1992, p.14).

\footnotetext{
${ }^{14}$ Tradução livre do original: If the camera obscura, as a concept, subsisted as an objective ground of visual truth, a variety of discourses and practices - in philosophy, science, and in procedures of social normalization - tend to abolish the foundations of that ground in the early nineteenth century. In a sense, what occurs is a new valuation of visual experience: it is given an unprecedented mobility and exchangeability, abstracted from any founding site or referent.
} 
ParaAumont (2004, p.48), mais focado na questão da representação gráfica, as mudanças em questão consistiam principalmente em uma "liberação" dos esquemas pictóricos que definiam o que era "representável". Ele enfatiza, no fazer artístico, a "passagem do esboço - registro de uma realidade já modelada pelo projeto de um futuro quadro - ao estudoregistro da realidade 'tal como ela é', por ela mesma".

Peter Galassi [...] nota a mobilidade ativa da pirâmide visual que fundaria esse desenvolvimento do estudo: uma concepção do mundo como campo interrompido de quadros potenciais, esquadrinhados pelo olhar do artista que o percorre, o explora e repentinamente pára para recortá-lo, "enquadrá-lo". Só é preciso dar um passo para ver nisso - é a tese de Galassi - a chave do aparecimento de uma ideologia fotográfica da representação: a máquina fotográfica como encarnação dessa mobilidade enfim encontrada. (AUMONT, 2004, p.49).

Esta passagem do esboço ao estudo e a questão de uma "ideologia fotográfica" servirão como base para duas reflexões. A primeira remete a outra dimensão da mesma transformação, que, acreditamos, pode ser representada pela passagem do pitoresco ao fotogênico. Aumont, na obra citada, aborda-a de uma maneira bastante interessante - há uma passagem, diz ele, da procura do ordinário (esquemas pictóricos) no extraordinário (uma nova e maravilhosa vista, por exemplo) para uma procura do extraordinário (o que, na fotografia e no cinema, aparece na noção de fotogenia) no ordinário (mundo cotidiano). Estaria aí, inclusive - na consonância com as transformações que se operavam nos regimes de visualidade -, tanto na análise de Aumont como na que propõe Morin (1997), a explicação do sucesso de Lumiére e do fracasso de Edison.

O espantoso êxito suscitado pelas tournées Lumière não se deve apenas, insiste Sadoul, à descoberta do mundo desconhecido, ao pitoresco, mas também à descoberta do cotidiano. Ao contrário de Edison, cujos primeiros filmes mostravam cenas de music-hall ou combates de boxe, Lumière teve a intuição genial de filmar e projetar como espetáculo o que não é espetáculo: a vida prosaica, os transeuntes no seu dia a dia. (MORIN, 1997, p.32). 
Realmente curiosa essa capacidade da imagem produzir um "efeito de real"15 que o próprio "real" não produz porque, sendo igual a si próprio, não pode representar-se. Mas é importante observar, recuperando o diagnóstico de Crary, que não se trata da objetividade, ou seja, do real em sua verdade supostamente objetiva, mas do efeito - o que importa é o seu impacto estético, subjetivo. Contrariando, portanto, muitas análises que tenderão a ver a mudança de um realismo pautado na objetividade da camera obscura por outro pautado no efeito subjetivo ocorrendo somente no início da pós-modernidade, o que as análises de Crary, Aumont e Morin nos mostram é essa transição, ao menos na representação visual, ocorrendo em pleno século XIX.

Esse diagnóstico será confirmado ainda por uma segunda reflexão impulsionada pela descrição de Aumont sobre a passagem do esboço ao estudo. Ela remete a uma possível base comum entre a fotografia e o impressionismo - como o próprio nome do movimento diz; aqui o que importa é a realidade como ela aparece para o pintor/observador, a impressão que este tem da realidade e que tenta reproduzir na tela. Assim, veremos que a pintura impressionista também remete ao estudo de que nos fala Aumont se observamos que a "realidade tal como ela é" e a "realidade como ela aparece para um observador" começam a se confundir por volta desta mesma época. Como nota Crary (1992), a relação entre visão e realidade está mudando radicalmente no início do século XIX - há uma oposição entre um entendimento da visão como processo "objetivo" de captura da realidade e um "novo" entendimento da mesma como "subjetiva", a imagem como produção do corpo e da mente a partir de estímulos.

Podemos citar a teoria da visão de Goethe, fundada no estudo das afterimages ${ }^{16}$, como um marco deste novo paradigma. Crary afirma que, por volta de 1820 , as pesquisas científicas ligadas às afterimages

\footnotetext{
${ }^{15}$ A expressão "efeito de real" é utilizada por Jaguaribe (2007).

${ }^{16}$ As afterimages ou "pós-imagens" são imagens que persistem após sua suposta "fonte" ter desaparecido, tal como quando olhamos para uma luz e depois para outro lugar menos iluminado e vemos algumas manchas no lugar onde antes víamos luz. Isso é fácil de notar, por exemplo, quando lemos um texto escrito em branco sobre fundo preto na tela do computador.
} 
proliferavam e que os experimentos relacionados a tais pesquisas acabaram dando origem aos mais diversos dispositivos ópticos. "Agrupando todos eles [os dispositivos] estava a noção de que a percepção não era instantânea e a noção de uma disjunção entre olho e objeto." (CRARY, 1992, p.104, tradução livre do original).

Esses dispositivos ópticos que mencionamos se difundiram rapidamente e se transformaram em populares formas de entretenimento - fenômeno que evidencia a imbricação entre produção intelectual e práticas de olhar, as duas colaborando na estruturação do que estamos chamando de regimes de visualidade.

Vejamos alguns deles: o thaumatrópio é um disco com dois desenhos, um de cada lado, feitos de modo que se completem - um passarinho de um lado e uma gaiola de outro, por exemplo. Ao se girar o disco rapidamente, tem-se a impressão de que os dois desenhos formam um só - um passarinho dentro de uma gaiola, no exemplo citado. O zootrópio (Figura 2) consiste em um cilindro com desenhos sequenciais na parte interna e perfurações. Quando o cilindro é girado ao redor de seu eixo, o observador enxerga rapidamente, através dos buracos, cada uma das imagens, tendo a sensação de ver uma imagem em movimento. $\mathrm{O}$ estereoscópio (Figura 2) é um dispositivo que "direciona" o olhar, fazendo com que cada olho "veja" uma imagem diferente. Cada imagem é apenas ligeiramente diferente da outra, copiando as diferenças entre as vistas dos dois olhos, de modo que, diante das duas imagens, vistas separadamente, tem-se a sensação de ver apenas uma imagem tridimensional.

\section{Figura 2 -Estereoscópio (esquerda) e zootrópio (direita)}
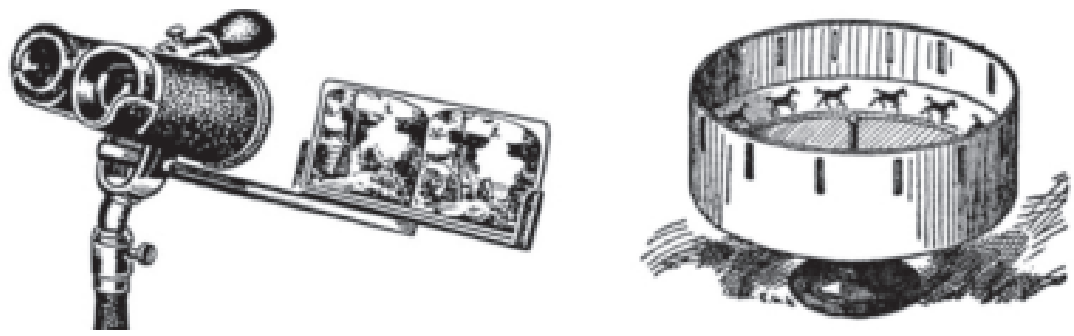
Os três servirão como representantes de duas "descobertas". Os dois primeiros dispositivos relacionam-se à "persistência retiniana" - "descobre-se" que a percepção não é instantânea e que continuamos a ver o que estávamos vendo alguns microssegundos atrás mesmo na ausência do objeto visto (como nas afterimages). Pouco importa, para nós, que, posteriormente, outras teorias afirmem que a impressão de movimento não tenha nada a ver com persistência retiniana. $\mathrm{O}$ estereoscópio, por sua vez, relaciona-se à "estereoscopia" "descobre-se" que intuímos a tridimensionalidade com base nas pequenas diferenças entre as imagens projetadas nas duas retinas. Duas "descobertas", portanto, que revelam claramente o novo status da imagem perceptual como criação do observador - i.e. de seu corpo e de sua mente - e não mais como uma espécie de projeção da realidade nele (modelo da camera obscura).

Dos três dispositivos de que falamos, destaquemos, agora, o estereoscópio. Notemos, primeiro, que ele foi, provavelmente, o mais popular deles - como argumenta Crary (1992), normalmente esquecemos o papel central do estereoscópio nas práticas de consumo de imagens fotográficas do século XIX. ${ }^{17}$ Em segundo lugar, observemos que ele talvez seja, dentre os três, o que melhor demonstra que o "engano" do olhar relacionado a estes dispositivos é muito diferente do levado a cabo por um trompe l'oeil. ${ }^{18} \mathrm{O}$ que Aumont (2004, p.49, grifos do autor) vê acontecer na pintura do século XIX - a passagem "de uma pintura que se dirige ao espectador de modo denegatório, com a tentação permanente do trompe-l'oeil [...] a uma pintura que supõe expressamente o olhar do espectador" fica ainda mais explícito com o estereoscópio. O "engano" aqui não é tanto dessa entidade abstrata "olhar" (e menos ainda do olhar

\footnotetext{
${ }_{17}$ Curioso notar, neste sentido, a ampla e repentina "volta" da estereoscopia em pleno século XXI, como uma prática diferenciada de consumo de filmes em salas de cinema e com a utilização de óculos mais elaborados que os de papel, costumeiramente usados em parques de diversão e outros lugares específicos que nunca deixaram de exibir os "filmes 3D", como são chamados.

${ }^{18}$ Para uma explicação rápida, digamos que são chamadas de trompe l'oeil aquelas pinturas que se aproveitam do ambiente em que se inserem e do ângulo em que serão vistas para "enganar" o olhar, passando-se por objeto "tridimensional". Por exemplo, uma porta pintada em tamanho real em um muro que pudesse ser confundida com uma porta passível de ser aberta.
} 
monocular e imóvel do modelo camera obscura) quanto do corpo/mente do observador - o corpo, agora, considerado em suas particularidades: dois olhos separados por uma distância mais ou menos homogênea e, cognitivamente, uma forma mais ou menos comum de agrupar os estímulos dos dois olhos em uma única imagem coerente.

Com esta análise do novo status do olhar, agora corporificado, voltamos às linhas mais gerais da "virada" que estamos analisando. Claramente, a corporificação do olhar está intimamente ligada à possibilidade da desvinculação da sensação visual e da imagem já significada pela razão, problemática esta que aparece tanto na proposta de "mobilização do olhar" de Aumont quanto no "desenraizamento da visão" proposto por Crary (1992). Os dois tratam de um descolamento da imagem visual, seja a imagem perceptual seja a imagem gráfica, de sua função representativa/significante. Em Aumont (2004), isso é bastante claro. Até o final do século XVIII, diz o autor, "há sempre, sob a representação da natureza, um texto, mais ou menos próximo, mais ou menos explícito, mas que explica sempre o quadro e lhe dá seu verdadeiro valor”. (AUMONT, 2004, p.50). A partir do início do século XIX, esse texto se apaga e a "janela" da imagem agora se abre para um mundo puramente estético - isto é, de uma estética autônoma e que se justifica, em parte, por si mesma.

Crary aponta descolamento semelhante quando nota que, até o início do século XIX, não fazia sentido falar em uma imagem visual "pura" essa imagem vista por um suposto "olho inocente" que procuravam Cézanne e os impressionistas e sobre a qual teorizava Ruskin -, pois a "sensação" não podia ser separada da atividade da razão. Seria só a partir do início do século XIX, com as teorias subjetivistas da visão das quais falamos acima, que se poderia separar a sensação visual de sua elaboração e significação pela razão ${ }^{19}$.

\footnotetext{
${ }^{19}$ Sabemos, é claro, que Kant já no século XVIII teoriza tal separação com a ideia de uma faculdade sensível separada da faculdade reflexiva/conceitual. Mas esse pensamento, de acordo com os autores estudados neste artigo, só começa a permear as práticas socioculturais de maneira mais generalizada no século XIX.
} 
Seguindo tal linha de raciocínio e vendo esse "descolamento" como um fenômeno generalizante que une as análises de Crary e Aumont, é impossível não lembrar da "descontinuidade epistêmica" que Foucault localizou também no início do século XIX e que marcaria o fim do que ele denominou "pensamento clássico". O fim deste, escreve o filósofo, "coincidirá com o recuo da representação, ou, antes, com a liberação, relativamente à representação, da linguagem, do ser vivo e da necessidade [e, acrescentaríamos, da imagem]". (FOUCAULT, 2007, p.289).

Foucault (2007) não enfoca muito explicitamente a imagem, mas demonstra que o "descolamento" do qual falávamos não se opera apenas no campo da visualidade, e sim no da representação de modo geral.

Se a imagem-intuição (ou imagem perceptual) ganha certa autonomia em relação ao entendimento que a transforma em imagem inteligível, imagem de algo, Foucault afirma que a linguagem, analogamente, libera-se do conhecimento, do trabalho de significação que antes a encobria.

A partir do século XIX, a linguagem se dobra sobre si mesma, adquire sua espessura própria, desenvolve uma história, leis e uma objetividade que só a ela pertencem. [...]. Conhecer a linguagem não é mais aproximar-se o mais perto possível do próprio conhecimento. (FOUCAULT, 2007, p.409-410).

E também a questão da corporificação do olhar (olhar que pertencerá, a partir de então, a um homem) que aparece na análise foucaultiana em suas linhas mais gerais: "na representação, os seres não manifestam mais sua identidade [como poder-se-ia supor que fariam no modelo clássico, da visão objetiva], mas a relação exterior que estabelecem com o ser humano". (FOUCAULT, 2007, p.431). Ou seja, a realidade empírica não é mais vista como um "em si" objetivo, mas como aquilo que aparece para nós.

No esforço de relacionar a "virada imagética" do século XIX que descrevemos neste artigo com mudanças mais gerais de mentalidade, podemos fazer referência também aos estudos de Charles Taylor (2005). Para Taylor, por volta do fim do século XVIII, a relação que se 
estabelecia com as coisas, pautada principalmente pelos arquétipos, se transforma de vez (pois trata-se de um processo que já estava em pleno desdobramento desde muito antes) em uma relação pautada na individualidade da coisa, destacando, assim, sua aparência nela mesma, sem remissão necessária a uma instância que a definisse (arquétipo). É por isso, explica Taylor, que a percepção de anacronismo de nossos antepassados era tão distante da nossa: "[na idade média,] a Virgem Maria podia aparecer vestida como a filha de um comerciante da Toscana. Hoje isso nos parece estranhamente incongruente, mas na época deve ter sido muito natural". (TAYLOR, 2005, p.372).

Sentimos a incongruência quando Maria tem os traços de uma toscana do século XIII em vez dos de uma judia do século I porque, para nós, ela é essa mulher em particular, cuja localização na história é crucial para o que ela foi. Mas, numa mentalidade em que seus traços eram assim, a Mãe de Deus gravita facilmente na direção de um arquétipo; e, como tal, está eqüidistante de todas as eras e, assim, pertence igualmente a todas elas. (TAYLOR, 2005, p.373).

Essas breves referências aos estudos de Foucault e Taylor, além de oferecerem mais um suporte para a localização de uma "virada imagética" no século XIX - pois mostram sua consonância com transformações de mentalidade mais amplas no seio da cultura ocidental da época -, levam-nos de volta ao início do texto e à questão do realismo. Os trechos citados, juntamente com a argumentação desenvolvida ao longo do trabalho, explicitam uma vez mais os problemas da noção de "realismo" entendida como uma categoria objetiva, isto é, que diz respeito a uma maior ou menor semelhança absoluta com uma realidade previamente dada.

Para que o realismo fotográfico e cinematográfico faça sentido, é preciso, antes de qualquer coisa, que encaremos a imagem como a reprodução de algo visto por alguém (ou de algo que seria visto por um homem se seu olho estivesse no lugar da câmera fotográfica), tal como foi visto em sua particularidade empírica. E, evidentemente, não é que 
tenhamos que nos forçar em um dado momento a vê-la de tal maneira, mas sim que aprendamos em nossa vivência sociocultural a ver as coisas e as imagens em um regime de visualidade que encare as imagens e suas relações com as coisas da maneira descrita acima, e que classifique as imagens como realistas com base nesse registro, potencializando nossa capacidade de sentir um "efeito de real" ao ver certos tipos de imagem.

Assim, como mostramos ao longo do artigo, a emergência da fotografia como imagem realista por excelência não poderia ser explicada apenas por categorias internas à própria imagem ou à tecnologia que a produz. Seria preciso que mudanças nos regimes de visualidade convergissem com as mudanças tecnológicas para o aparecimento da fotografia. Foi a partir de tal base, conforme explicitado no início do trabalho, que, ao longo deste artigo, mostramos algumas mudanças nas formas de entender a representação e analisamos como tais transformações epistêmicas impactaram novas formas de ver, impulsionando a "virada imagética" do século XIX, esta que oferece as bases para o realismo fotográfico e cinematográfico.

\section{Referências}

AUMONT, Jacques. O olho interminável: cinema e pintura. São Paulo: Cosac Naify, 2004.

BENJAMIN, Walter. A obra de arte na época de sua reprodutibilidade técnica. In: ADORNO, Theodor W. et al. Teoria da Cultura de massa. Tradução de Carlos Nelson Coutinho. São Paulo: Paz e Terra, 2000, p.221-254.

CRARY, Jonathan. Techniques of the observer: on vision and modernity in the $19^{\text {th }}$ century. Cambridge: MIT press, 1992. 
DEREK WOOD, R. The diorama in Great Britain in 1820s. History of photography, London, v.17, n.3, 1993, p.284-295. Disponível em: $<$ http://www.midley.co.uk>. Acesso em: 7 maio 2011.

FLUSSER, Vilém. Filosofia da caixa-preta: ensaios para uma futura filosofia da fotografia. Rio de Janeiro: Relume Dumará, 2002.

FOUCAULT, Michel. As palavras e as coisas. 9.ed. São Paulo: Martins Fontes, 2007.

GOMBRICH, Ernst Hans. Arte e ilusão: um estudo da psicologia da representação. 4.ed. São Paulo: Martins Fontes, 2007.

HOCKNEY, David. O conhecimento secreto. São Paulo: Cosac Naify, 2002.

JAGUARIBE, Beatriz $\mathbf{O}$ choque do real: estética, mídia e cultura. Rio de Janeiro: Rocco, 2007

MACHADO, Arlindo. Pré-cinemas e pós-cinemas. Campinas: Papirus, 1997.

MITCHELL, W. J. T. Como caçar (e ser caçado por) imagens: entrevista com W. J. T. Mitchell. Entrevista concedida a Daniel Portugal e Rose de Melo Rocha. E-compós, Brasília, v.12, n.1, jan./abr. 2009. Disponível em: $<$ http://www.compos.org.br/seer/index.php/e-compos/ article/view/376/327>. Acesso em: 10 maio 2011.

.What do pictures want?: the lives and loves of images. Chicago: University of Chicago Press, 2005.

. Picture theory. Chicago: The University of Chicago press, 1994. 
MORIN, Edgar. O cinema ou o homem imaginário. Lisboa: Relógio d'agua, 1997.

SACKS, Oliver. Um antropólogo em Marte: sete histórias paradoxais. São Paulo: Companhia das Letras, 1995.

SARMIENTO, Guilherme. Névoas, sombras e estranhamento: as phantasmagorias sob a óptica do romantismo. Contracampo, Rio de Janeiro, n. 39, 2002. Disponível em: < http://www.contracampo.com.br/ 39/fantasmagoria1.htm>. Acesso em: 7 jul. 2009.

SCHOPENHAUER, Arthur. Sobre a visão e as cores. São Paulo: Nova Alexandria, 2003.

TAYLOR, Charles. As fontes do self. 2.ed. São Paulo: Loyola, 2005. 